\title{
Trabalho religioso e mercado religioso no meio pentecostal
}

\author{
Trabalho religioso y mercado religioso no meio pentecostal \\ Religious work and religious market in Pentecostal milieu
}

\author{
James Washington Alves dos Santos ${ }^{1}$
}

\begin{abstract}
Resumo
Este artigo propõe estudar os conceitos de trabalho e mercado religiosos no meio pentecostal (Assembleia de Deus) e sua aplicação em relação ao contexto da cidade de Palmeira dos Índios, em Alagoas. Neste sentido, foi feita uma articulação que envolve produção simbólica, desigualdade social e relações sociais, a fim de fundamentar esta forma de trabalho enquanto poder de consagração dado aos agentes religiosos, possibilitando a eles o monopólio do serviço que prestam. A contribuição de um projeto como este para o entendimento dos mecanismos que circulam as relações humanas é algo contundente, visto que o monopólio da produção de bens religiosos é uma forma estratégica de dominação, que tem fundamento na separação arbitrária entre produtores e consumidores de simbologia religiosa. Assim, fazemos menção ao contexto político-religioso em Alagoas, definindo o que vem a ser o trabalho e o mercado religiosos, os agentes envolvidos, as relações de aliança e conflito entorno desta questão e a importância do fenômeno religioso na atualidade. É importante ressaltar que o problema de pesquisa que temos é a defesa da autonomia da religião, visando romper com a dicotomia entre idealismo e materialismo na religião. Isso possibilita em nossa opinião, ver a religião como espaço onde ocorre a crença pessoal no transcendente e ao mesmo tempo a presença da desigualdade social em sua própria estrutura.
\end{abstract}

Palavras-Chave: trabalho, mercado, religião.

\section{Resumen}

Este artículo propone un estudio sobre los conceptos de trabajo y el mercado religioso no medio pentecostal (Assembleia de Deus) y su aplicación en relación con el contexto de la ciudad de Palmeira dos Índios, en Alagoas. En este sentido, se ha hecho una articulación que envuelva la producción de simbólica, la desigualdad social y las relaciones sociales, una forma de fundar esta forma de trabajo de poder de consagración dado a los agentes religiosos, posibilitando el monopolio del servicio que prestam. Una contribución de un proyecto como este para el entendimiento de los mecanismos que circulan como relaciones humanas es algo contundente, visto que el monopolio de la producción de bienes religiosos es una forma estratégica de la dominación, que tiene fundamento en la separación entre los productores y los consumidores de simbología religiosa. Assim, la relación de género en el contexto político-religioso en Alagoas, definiendo lo que viene a ser el trabajo y el mercado religioso, los agentes involucrados, como las relaciones de conflicto y conflictos alrededor de la cuestión y un valor del fenómeno religioso en la actualidad. Es importante resaltar que el problema de la investigación que tienen una defensa de la autonomía de la religión, visando romper con una dicotomía entre idealismo y materialismo en la religión. Esta posibilidad en nuestra opinión, en un ambiente religioso como el espacio donde se produce una crença personal no transcendente y en el mismo tiempo una presencia de desigualdad social en su propia estructura.

Palabras Clave: trabajo, mercado, religión.

\section{Abstract}

This article proposes to study the concepts of work and religious market in the Pentecostal environment (Assembly of God) and its application in relation to the context of the city of Palmeira dos Índios in Alagoas. In this sense, an articulation was made that involves symbolic production, social inequality and social relations, in

\footnotetext{
${ }^{1}$ Professor do Instituto Federal - Alagoas (IF-AL) e aluno de doutorado em Ciências Sociais pela UNESP; Araraquara, São Paulo, Brasil; james.was@hotmail.com. Trabalho apresentado no I Seminário LatinoAmericano de Estudos em Cultura - SEMLACult, Foz do Iguaçu/PR, Brasil, 2017.
} 
order to base this form of work as a power of consecration given to religious agents, enabling them to monopolize the service they provide. The contribution of a project such as this to the understanding of the mechanisms that circulate human relations is something forceful, since the monopoly of the production of religious goods is a strategic form of domination, based on the arbitrary separation between producers and consumers of religious symbols. Thus, we make reference to the political-religious context in Alagoas, defining what is the religious work and market, the agents involved, the alliance and conflict relations surrounding this issue and the importance of the religious phenomenon in the present time. It is important to emphasize that the research problem that we have is the defense of the autonomy of religion, aiming to break with the dichotomy between idealism and materialism in religion. This makes it possible, in our opinion, to see religion as the space where personal belief in the transcendent occurs and at the same time the presence of social inequality in its own structure.

Keywords: work, market, religion.

\section{Introdução}

O artigo em questão analisa do ponto de vista sociológico o que vem a ser o trabalho e o mercado religiosos e sua relação com a existência de relações de poder no meio pentecostal, o que envolve algumas categorias de agentes (diáconos, presbíteros, evangelistas e pastores), bem como a dicotomia entre produtores e consumidores de bens religiosos ${ }^{2}$.

Quando falamos do conceito de trabalho religioso estamos nos referindo ao exercício do poder de consagração conferido aos agentes religiosos, o que possibilita o monopólio sobre a produção de bens sagrados em detrimento à camada conhecida como leiga, ou seja, desapropriada da capacidade de criar simbologia religiosa e destinada a ser um grupo consumidor desses bens (BOURDIEU, 2009). Já o mercado religioso é definido como a mercantilização dos bens sagrados, atendendo as demandas dos grupos que recorrem à religião institucionalizada (BERGER, 1985).

$\mathrm{Na}$ base desta discussão está a formação e composição dos cargos de liderança religiosa. Para a Assembleia de Deus, a escolha de homens ${ }^{3}$ para compor sua liderança é feita utilizando critérios de cunho espiritual e social, sendo eles: ser batizado nas águas; possuir o dom espiritual da glossolalia enquanto sinal de poder; demonstrar interesse pelas sagradas escrituras e o trabalho eclesial; ser dizimista; demonstrar bom relacionamento familiar; apresentar exame da sanidade mental; apresentar documentação sobre antecedentes criminais; apresentar documentação de isenção de dívidas no SPC-SERASA e nos casos de evangelista e pastor, ter no mínimo o curso básico de Teologia (que dura 2 anos).

Já em relação a algumas outras denominações, temos o seguinte comentário:

\footnotetext{
${ }^{2}$ Entendemos o termo "bens religiosos" como os elementos materiais e simbólicos ligados a religião que são produzidos e servem de referência para a crença no meio pentecostal (o púlpito, a bíblia, as vestes, o cabelo e a forma regrada de conduta são os exemplos mais típicos).

${ }^{3}$ É vetada a candidatura das mulheres com base na tradição apostólica.
} 
$\mathrm{Na}$ igreja Congregacional, o aluno pode fazer o curso de Educação Teológica (de nível técnico) ou de Bacharelado, para o qual é obrigatório o segundo grau. 'Após quatro anos de estudo, ainda há o estágio de um ano, monitorado por uma comissão. A ordenação só ocorre depois desse período, e ainda depende de aprovação em prova escrita e numa arguição', esclarece Paulo Leite da Costa, presidente da União das Igrejas Evangélicas Congregacionais do Brasil. [...] A igreja Evangélica de Confissão Luterana do Brasil só ordena ao ministério o candidato que tem curso de bacharelado em Teologia. Além disso, também exige um período prático de habilitação de um ano. [...] Na igreja Presbiteriana do Brasil, 'quem se sente vocacionado para o ministério deve ser examinado primeiramente pelo conselho da igreja local', explica o reverendo Guilhermino Cunha, presidente do Supremo Concílio da Igreja Presbiteriana do Brasil. 'O aspirante é enviado ao presbitério, e, se aprovado, pode fazer o vestibular para o seminário'. O curso superior de Teologia, ministrado em um dos seis institutos da denominação espalhados pelo Brasil, tem duração de cinco anos, mas só entra quem tem segundo grau completo e é aprovado no exame vestibular específico. Depois de formado, o candidato é novamente examinado pelo presbitério e, sendo aprovado, inicia um período de licenciatura de um a três anos, durante o qual pode pregar o evangelho, mas tutorado por um pastor. [...] Na igreja Metodista do Brasil a formação de um pastor metodista tem duas fases: um curso básico, de dois anos, e o de Teologia, que dura mais três. Após formado, o teólogo passa por um período de acompanhamento que dura quatro anos, quando é observado por uma comissão ministerial. Somente depois de satisfeitas todas estas etapas - que podem durar até dez anos - é que o candidato é ordenado pastor. (VINDE, $\mathrm{n}$. 10, ago./1996, apud. MARIANO, 2001, p. 336-337).

Enquanto nos exemplos mencionados acima, as exigências para alcançar o ministério $^{4}$ são a formação teológica, estágios probatórios, provas, exames e arguições. $\mathrm{Na}$ Assembleia de Deus as exigências ganham outra dimensão, sendo predominantemente o domínio da Bíblia e da glossolalia (“as duas armas necessárias”), a formação básica em Teologia (com duração de 2 anos), além da "revelação divina" dada aos pastores desta denominação religiosa, que deve determinar a posição de cada fiel na hierarquia assembleiana e os documentos que comprovem o estado de saúde e a conduta do candidato.

Neste sentido, esta pesquisa define o que vem a ser o trabalho e o mercado religiosos e ao mesmo tempo analisa, por meio de pesquisa bibliográfica, observação participante e

\footnotetext{
${ }^{4}$ Cabe ressaltar que o termo "ministério", possui na Assembleia de Deus dois significados: o primeiro refere-se à estrutura administrativa da igreja. Ministério é o nome dado para o conjunto dos diáconos, presbíteros, evangelistas e pastores que organizam as atividades eclesiais. O segundo significado diz respeito ao "chamado", que, crê-se, alguns fiéis tenham recebido do próprio Deus para efetuar alguma atividade. O fiel que prega, canta em um coral ou executa solos musicais; que profetiza e que atua com eficiência em um departamento da igreja, para citar alguns exemplos, o faz porque Deus o "chamou" para este trabalho, porque Deus lhe deu aquele ministério.
} 
entrevista, o seu desenvolvimento no Nordeste brasileiro $^{5}$ por meio da Assembleia de Deus. Isso implica considerar que este campo de pesquisa se revela importante em termos etnográficos, haja vista a existência de uma série de questões que precisam ser analisadas in loco. Trata-se neste ponto de uma pesquisa de cunho qualitativo sobre o desenvolvimento e o crescimento da Assembleia de Deus e do segmento pentecostal.

\section{Os aspectos principais do trabalho e mercado religiosos}

$\mathrm{Na}$ Sociologia, o conceito de trabalho esteve ligado em seu período clássico às ideias de Karl Marx, e com isso, diretamente relacionado ao exercício das aptidões físicas e mentais na execução das atividades laborais, expressas através da própria criatividade humana.

É verdade que também o animal produz. Constrói para si um ninho, habitações, como a abelha, castor, formiga etc. No entanto, produz apenas aquilo de que necessita imediatamente para si ou sua cria; produz unilateral[mente], enquanto o homem produz universal[mente]; o animal produz apenas sob o domínio da carência física imediata, enquanto o homem produz mesmo livre da carência física, e só produz, primeira e verdadeiramente, na [sua] liberdade [com relação] a ela; [...] $\mathrm{O}$ animal forma apenas segundo a medida e a carência da espécie à qual pertence, enquanto o homem sabe produzir segundo a medida de qualquer espécie, e sabe considerar, por toda a parte, a medida inerente ao objeto; o homem também forma, por isso, segundo as leis da beleza. (MARX, 2004, p. 85)

Neste sentido, o trabalho constituiu-se como meio fundamental para a produção material, evidenciando o direcionamento da energia humana na construção e desenvolvimento dos objetos. Assim, o eixo infra-estrutural, de produção da vida material, toma a primazia em relação ao eixo superestrutural, que privilegia a produção de ideias e elementos simbólicos, ainda que o segundo seja tão importante quanto o primeiro. Não bastando isso, a interpretação é de que o eixo superestrutural serve simplesmente como base para a existência de uma falsa consciência do mundo, alienando os indivíduos e permitindo a manutenção de um aparato que visa à submissão às condições de dominação.

Partindo deste pressuposto, a religião, como produtora de sentido e elementos simbólicos, estaria diretamente ligada à formação da consciência, sendo usada como artifício eficiente a dominação política. Isso possibilitou a abertura de um "abismo" entre os conceitos

\footnotetext{
${ }^{5}$ Levando em consideração os estudos já desenvolvidos, podemos dizer que a Assembleia de Deus costuma manifestar seu governo eclesiástico de forma a privilegiar a ação e o carisma dos agentes escolhidos, o que proporciona formas variadas de governança (um ethos eclesiástico). Isso acaba por criar a possibilidade dos pastores e demais lideres se comportarem como verdadeiros bispos, exercendo um poder controlador na comunidade que pastoreiam (FRESTON, 1999).
} 
de trabalho e religião dentro do pensamento sociológico (isso em Marx, pois a ética protestante em Weber nos dá outro sentido). Contudo, o que pretendemos fazer é a aproximação entre estes dois conceitos, mostrando que a ideia de trabalho pode também ser conectada ao ato de se produzir símbolos religiosos sendo estes elementos, necessários socialmente, visto que da mesma forma que as pessoas carecem dos produtos essenciais ligados à atividade laboral (gêneros alimentícios, vestuário e utensílios), também carecem de sentido e de motivação na execução de suas atividades diárias.

Desta forma, a religião se constitui como produtora de elementos simbólicos que formam uma totalidade coerente, capaz de formar explicações e dar sentido à vida. "As categorias de sagrado e profano, material e espiritual, eterno e temporal, do céu e da terra, funcionam como bases sobre as quais se estabelecem os pares de oposição utilizados na linguagem e que servem de elementos construtores da experiência vivida" (TEIXEIRA, 2007, p. 179). Disso advém a necessidade de construção e consumo desses "bens religiosos". No entanto, não basta que o conjunto de práticas e esquemas de pensamento religiosos estejam coerentemente estruturados para exercer sua função, faz-se necessário que estes esquemas se inculquem nos membros de uma dada sociedade, a fim de moldar seu comportamento. Os esquemas de pensamento devem se inscrever nas consciências individuais e nelas se incorporarem como se fossem naturais, transformando-se no que Bourdieu chamava de habitus $^{6}$

Por isso defendemos a tese de Bourdieu na qual o trabalho religioso é definido através do chamado "poder de consagração" 7 ", que a seu ver promove a "absolutização do relativo e a legitimação do arbitrário" (BOURDIEU, 2009, p. 46), indicando desta forma a ação da religião sobre as instituições sociais. Essa força exercida pelos agentes religiosos é capaz de transfigurar as instituições e é isso que procuramos evidenciar, pois o que é considerado construção humana, culturalmente condicionada, deixa de ser assim, tornando-se sobrenatural e inscrita na natureza das coisas. Este mesmo efeito pode ser aplicado não só às instituições, mas também a pessoas, que passam a ser encaradas como fruto do desígnio divino ou inseridas dentro de uma ordem intocável. Assim a religião atua como elemento estruturante da sociedade, transformando o "assim é" em "assim deve ser".

\footnotetext{
${ }^{6}$ Neste sentido, o habitus é um sistema de disposições duráveis e transponíveis que integra todas as experiências passadas, funcionando a cada momento como uma matriz de percepções, de apreciações e de ações, que torna possível a realização de tarefas infinitamente diferenciadas, graças às transferências analógicas de esquemas (BOURDIEU, 1989).

${ }^{7}$ Cabe ressaltar que Bourdieu, quando formulou o seu pensamento, estava analisando o catolicismo europeu de sua época. Contudo, podemos ampliar este estudo em relação ao contexto brasileiro, adquirindo desta forma subsídios para o entendimento do fenômeno religioso como estrutural e ao mesmo tempo estruturante da sociedade.
} 
Segundo Bourdieu (Ibid., p. 32), o efeito de consagração se faz presente de duas formas:

a) Através de suas sanções santificantes, converte em limites legais os limites e as barreiras econômicas e políticas efetivas e, em particular, contribui para a manipulação simbólica das aspirações;

b) E inculca um sistema de práticas e de representações consagradas cuja estrutura (estruturada e estruturante) se reproduz sob uma forma transfigurada, mesmo sendo produto das relações humanas, tornando desta forma irreconhecível a estrutura das relações econômicas e sociais vigentes.

Esta transformação é denominada por Bourdieu (Ibid., p. 33) de "Alquimia Simbólica", pois reveste o que é humano (arbitrário e condicionado ao tempo) em algo sagrado (inquestionável e perene), desempenhando a função simbólica de conferir a ordem social um caráter transcendente. Neste ponto reside sua eficácia simbólica e ao mesmo tempo sua função eminentemente política o que dá aos agentes religiosos força em relação às atividades e funções desempenhadas.

Acreditamos então que o contexto religioso assembleiano se coloca como um terreno fértil a manipulação simbólica das aspirações e ao uso do poder de consagração por parte dos agentes religiosos. Agentes estes envolvidos com esta produção de sentido e que seguem em nosso trabalho uma categorização proposta por Weber (2009, p. 279), que os apresenta enquanto sacerdotes ${ }^{8}$.

Desta forma a concentração do trabalho religioso nas mãos de agentes especializados é parte do processo geral de divisão social do trabalho, pois os produtores de bens simbólicos ligados à religião são dispensados do trabalho material. Estes são reconhecidos como os únicos habilitados a produzir, reproduzir, gerir e distribuir os bens religiosos e só se constituem enquanto tais, na medida em que os outros membros da mesma sociedade sejam destituídos de tal capacidade de trabalho religioso, o que resulta na:

[...] gestão dos bens de salvação por um corpo de especialistas religiosos, socialmente reconhecidos como detentores exclusivos da competência

\footnotetext{
${ }^{8} \mathrm{O}$ sacerdote, agente aqui apresentado, é por excelência o agente da religião estabelecida, aquele que reproduz e pereniza um sistema de crenças e ritos sagrados, inserindo-se na rotina social, de modo que a religião se incorpore em cada membro dessa sociedade e torne-se um hábito que ninguém questiona. Daí a sua tendência a atuar em igrejas em instituições eclesiásticas, das quais ele é funcionário e das quais ele recebe o carisma próprio à sua função religiosa.
} 
específica, que é necessária a produção de um corpus deliberadamente organizado de saberes secretos, a constituição de um campo religioso acompanha a desapropriação objetiva daqueles que dele são excluídos e que se transformam por esta razão em leigos (BOURDIEU, 2009, p. 39).

Uma vez constituído o campo religioso, ele será movido pela busca do completo domínio do trabalho religioso por um conjunto de agentes especializados. Embora tal objetivo nunca seja alcançado perfeitamente, a estratégia dos agentes especializados em relação aos leigos estaria pautada pelo combate a toda produção religiosa de auto-consumo, de modo que o corpo de agentes socialmente definidos como religiosos, alcance o controle completo sobre a produção de bens religiosos de uma dada sociedade. Tal situação repousa no fato de que os agentes especializados no sagrado não precisam mais se ocupar com a produção de sua existência material (pois seu sustento é assegurado pelos serviços religiosos que estão socialmente autorizados a desempenhar), isso evidencia seu poder propriamente religioso de “consagração" que, como vimos, é ao mesmo tempo eminentemente político (naturaliza ou diviniza as instituições e a ordem estabelecida).

Cabe ressaltar no término desta exposição dos fundamentos teóricos, a crença que temos no processo de fortalecimento do campo religioso no Brasil, não valorando se este está indo no rumo certo ou errado. A análise que buscamos fazer é em relação a sua existência e seu poder social e político ${ }^{9}$. Assim vamos circunscrevendo o espaço para o debate sobre o que vem a ser o trabalho religioso enquanto conceito sócio-antropológico, trazendo também a discussão sobre os agentes que o fazem, bem como a ideia de fortalecimento deste campo e sua relação com a questão das relações sociais.

\section{Aspectos formais da pesquisa}

Nosso objetivo é mostrar como os conceitos de trabalho e mercado religiosos se aplicam ao pentecostalismo brasileiro por meio da Assembleia de Deus. Definindo os conceitos de trabalho e mercado religiosos; relacionando estes conceitos com a ideia de campo religioso; mostrando os agentes envolvidos; os bens religiosos em jogo, bem como os limites da separação entre produtores e consumidores de simbologia religiosa.

\footnotetext{
${ }^{9}$ Cabe lembrar que este fortalecimento põe em cheque a ideia de secularização enquanto ruína da religião, bastante debatida por teóricos como Aquaviva (1992), com sua ideia de eclipse do sagrado; Dobbelaere (1981) com a ideia de secularização multidimensional (incluindo as esferas: societal, institucional e individual), como também Luckmann (1969), com sua "religião invisível".
} 
Como fundamento metodológico, utilizamos a pesquisa de campo (em 6 locais pertencentes à denominação religiosa em estudo), baseada na realização de entrevistas semiestruturadas e em observação participante, isso com o auxilio da pesquisa bibliográfica. A população estudada esta relacionada com a igreja evangélica Assembleia de Deus no Estado de Alagoas e quanto à escolha da cidade, fizemos opção pela cidade de Palmeira dos Índios ( $3^{\circ}$ maior campo eclesiástico e cidade onde reside o pesquisador). $\mathrm{O}$ fato de ter o campo religioso como base de estudo se justifica porque esta análise se baseia na ideia de formação e desenvolvimento do trabalho religioso num dado contexto, definindo assim suas características internas, agentes e agrupamentos participantes.

Neste sentido, não podemos negar que a etnografia possa contribuir de maneira significativa para o estudo do trabalho religioso no meio pentecostal, na medida em que temos como objeto principal o ser humano imerso em sua cultura e justamente a abordagem antropológica de base provém da ideia de uma "observação direta dos comportamentos sociais a partir de uma relação humana" (LAPLANTINE, 1988, p. 25). Deste modo a etnografia acaba sendo, literalmente, a descrição de um povo ou de uma dada estrutura de relações humanas, lidando com o coletivo e examinando os comportamentos interpessoais, as produções e as crenças do grupo. O nosso desafio foi o de promover um estudo de maneira pontual, observando os membros da Assembleia de Deus basicamente em seu cotidiano "nativo", possibilitando a descrição e interpretação de sua estrutura eclesiástica.

Priorizamos as entrevistas com os dirigentes de cada congregação, além das conversas informais com os fiéis. No caso dos dirigentes, eles são diáconos, presbíteros e pastores e poucos se colocaram disponíveis a conversar. Diante disso, reunimos informações de 6 deles (3 presbíteros, 2 diáconos e 1 pastor). Como há uma alta rotatividade dos dirigentes, por uma lógica administrativa do campo eclesiástico em Palmeira dos Índios, eles acabam por passar entre 1 mês a 1 ano em uma comunidade, sem criar laços efetivos com o povo, mesmo que os conheça de maneira menos formal em outros ambientes.

\section{Resultados e discussão}

Os resultados que pudemos alcançar neste trabalho foram:

Que a estruturação do trabalho religioso em Palmeira dos Índios tomou como base a ideia de vocação (chamado), justificando sua crença por meio da tradição bíblica e 
relacionando a mesma a questões de cunho moral e político, o que gera um status no meio social e eclesiástico.

Segue enquanto exemplo do que argumentamos acima, o relato do pastor que foi entrevistado:

A Bíblia fala em $\mathrm{Hb} 4.5$ em relação aos vocacionados para o ministério, que ninguém tome esta honra para si, a não ser aquele que é chamado como foi Arão. Arão foi o primeiro sumo sacerdote de Israel e a partir de Arão surgiu uma linhagem sacerdotal que é conservada até hoje pelo povo de Israel. Então para Arão e para todos nós é um grande privilégio, uma grande honra, eu vejo isso como uma grande honra. Ele quer chamar alguém, vocacionar alguém, chamar essa pessoa para estar exercendo um sacerdócio junto aos homens. Por que o ofício pastoral, tendo essa característica de um sacerdócio, eleva o homem a uma condição de representante de Deus na terra, que não é uma posição insignificante, pequena, o apóstolo Paulo diz que o obreiro, ele é um embaixador de Cristo na terra, e quando a gente faz uma análise desse cargo de embaixador, não é! Um indivíduo que é investido ou nomeado como embaixador de um país e enviado a outro, aquele indivíduo, ele tem todas as honras que o cargo lhe confere e também todos os direitos, todos os deveres que o cargo confere a ele como embaixador. Ele é o representante do seu país em uma terra estranha. Ele fala em nome do seu povo, em nome do seu governante, a palavra desse homem tem peso, tem valor. Ele é reconhecido como uma grande autoridade, então isso, em se tratando do ministério pastoral, para o homem, o homem mortal, o pastor, um homem mortal, claro! É um grande privilégio, é uma grande honra, eu sou representante de Deus diante dos homens, eu conduzo homens, o pastor pensa assim: eu conduzo homens a Deus, eu abro a porta de certa forma, abro a porta para outros terem acesso a Deus, eu sou um representante de Deus, o que eu faço, dentro da vontade de Deus, Deus aprova, Deus confirma, isso é maravilhoso (trecho de entrevista).

Por meio deste chamado é possível rotinizar o trabalho religioso por meio da ação sacerdotal dos ministros escolhidos, na medida em que eles reproduzem uma série de serviços para os leigos, mesmos que estes tenham algumas funções especificas. Disso resulta uma dicotomia interna ao campo religioso que separa produtores e consumidores de bens religiosos.

A nomeação (ordenação) para os cargos ministeriais funciona simbolicamente como uma "alquimia simbólica" na medida em que converte o profano em sagrado. Disso resulta a transformação social do indivíduo em "figura consagrada por Deus" (a serviço da igreja), mesmo sendo ungido por mãos humanas. $\mathrm{O}$ detalhe é que uma vez consagrado, o indivíduo adquire o chamado "efeito de consagração", podendo assim converter ideologicamente outros elementos em algo sagrado, isso por meio dos serviços que está autorizado a prestar. 
Esta situação gera em nossa pesquisa a constatação de que existe uma relação política na medida em que se institui uma elite religiosa capaz de exercer um governo que mistura: controle doutrinário, centralização administrativa e uso de dons e carismas próprios. O que gera uma tríade normativa alicerçada pela: doutrina bíblica, doutrina pastoral e autoridade espiritual, respectivamente.

Os mecanismos que são utilizados na Assembleia de Deus para a manutenção deste controle estão alicerçados na ligação entre as ideias de salvação, a obediência à doutrina, submissão ao chamado e gestão autocrática da igreja e dos carismas. Isso resulta numa autonomia administrativa e eclesial que mune o pastor de autoridade na medida em que se pode descentralizar a oferta dos serviços, possibilitando que os que se encontram abaixo da hierarquia o ajudem, contudo, paralisa a autonomia destes, na medida em que continua como orientador de todas as operações e decisões.

Neste contexto os símbolos servem para alicerçar a crença dos fiéis de que suas vidas só tem sentido se ligados a uma determinada comunidade, ou seja, a um mecanismo institucional de regulação, que tem como base formular uma regra dita coerente de crenças e expor as mesmas como a melhor das interpretações possíveis.

\subsection{Os aspectos próprios da carreira sacerdotal assembleiana}

É possível afirmação que todos os cargos na Assembleia de Deus apresentam atribuições gerais e são razoavelmente regrados. É incomum se queimar etapas na carreira de obreiro assembleiano, embora alguns fiéis, por transferência de outras igrejas ou necessidade da instituição possam ter a oportunidade de assumirem determinados postos ou passarem do menor ao maior posto na organização em um espaço de tempo mais curto que o normal. Caso um obreiro (diácono ou presbítero) de outra igreja evangélica transfira-se para a Assembleia de Deus, o cargo que ele possuía será reconhecido mediante a observância dos requisitos mencionados no Regimento Interno das Assembleias de Deus estaduais. Em geral, conforme a nossa pesquisa, as exigências seriam as seguintes:

a) documentos de identificação, e ter parecer favorável do Conselho Consultivo e de Ética;

b) certidões negativas expedidas por cartórios distribuidores criminais e cíveis da comarca de sua residência anterior, bem como informações de órgãos cadastrais de créditos; 
c) e passar ainda por um período mínimo de três, e, no máximo, seis meses de observação pelo obreiro local onde estiver congregando.

Em caso de reprovação, o candidato pode iniciar sua carreira novamente, desde que seja indicado para tal e desta forma, deverá partir da base da pirâmide hierárquica da Assembleia de Deus, obedecendo à seguinte ordem:

O primeiro nível na carreira eclesiástica de um fiel assembleiano do sexo masculino é o de auxiliar. O responsável pela congregação tem a liberdade de arregimentá-lo a qualquer tempo, destacando-o a partir de então para funções na igreja, como:

a) distribuição de folhetos com mensagens bíblicas;

b) porteiro;

c) recepcionista;

d) e dirigente de um departamento da igreja.

No entanto, a qualidade que pode distingui-lo dos demais fiéis é a de saber pregar na igreja, sendo normal um auxiliar receber em alguns momentos a incumbência de ser o preletor do culto. Por isso, a habilidade em manejar a "palavra de Deus" enquanto arma necessária é vista pelos demais obreiros e fiéis como sinal de vocação para o pastorado, uma marca que diferencia o aspirante a auxiliar dos demais membros da igreja, uma vez que são muitos os fiéis atuantes que também executam tarefas pertinentes aos auxiliares, mas não são reconhecidos como bons pregadores.

A oficialização é realizada em cerimônia de consagração, com duração de não mais que dez minutos, realizada durante um culto. $\mathrm{O}$ ato consiste no seguinte: o encarregado da congregação comunica o nome do fiel que será consagrado um auxiliar e solicita aos fiéis que os mesmos digam "amém" se concordam com o ato; é pedido para que o novo obreiro dirijase até o altar e ali ajoelhe-se, de costas para a igreja e de frente para os demais obreiros; é feita uma oração juntamente com a congregação, sacramentando assim o ato.

O segundo nível na hierarquia da Assembleia de Deus é o de diácono. Este é "convidado" a participar da escala de obreiros, formulada mensalmente pela secretaria da igreja, em que os diáconos e presbíteros que se dispuserem a participar da mesma são escalados de forma aleatória para iniciarem os cultos na congregação a que pertencem. Além disso, os regimentos internos das Assembleias de Deus indicam outras atividades, sendo estas: 

a) a distribuição dos elementos da Santa Ceia (pão e vinho);
b) o recolhimento das contribuições dos fiéis nos cultos;
c) a recepção dos cultuantes e visitantes;
d) a segurança interna dos locais de culto e reuniões;
e) e o atendimento das atividades filantrópicas.

O indicado ao diaconato deve ser membro da igreja por no mínimo 3 anos e deve possuir o dom da glossolalia (falar línguas estranhas). Deve também preencher uma ficha na qual são solicitados alguns dados pessoais e em alguns Estados, dar resposta às seguintes questões: "É batizado no Espírito Santo? Há quanto tempo? Trabalha? É dizimista? Vai continuar sendo? Há quanto tempo é crente? Há quanto tempo vem cooperando na obra da Deus? Alguma vez sofreu disciplina? Por quanto tempo? Pertenceu a outra denominação? Qual?”.

Ainda neste documento, o fiel deve dizer "sim" ou "não" ante a seguinte pergunta: "promete diante de Deus: cumprir com suas obrigações ministeriais; obedecer às orientações do ministério da igreja; estar presente no Culto dos Obreiros todas as terças-feiras, inclusive na Santa Ceia celebrada na igreja-sede, toda $1^{\mathrm{a}}$ terça-feira do mês; nunca causar tropeços, nem embaraços ou impedimento na obra do senhor; não se envolver em questões administrativas e exercer o cargo fielmente, segundo a orientação pastoral? ". A documentação em questão (com algumas variações de Estado para Estado) legitima a consagração, ao mesmo tempo em que torna-se reforço ao caráter simbólico do cargo, atribuindo ao portador da posição eclesial um status. Após preenchê-lo e assiná-lo, o indicado ao diaconato deve entregar o documento à secretaria da igreja juntamente com a seguinte documentação: Certidão negativa do sistema de proteção ao crédito (SPC-SERASA); Certidão negativa do tabelionato de protesto de títulos; Certidão negativa do cartório civil e criminal; comprovante de pagamento do dízimo dos últimos doze meses; Certidão de casamento e de sanidade mental.

Estes documentos são, então, repassados a convenção da igreja que acionará o Conselho Consultivo de Ética para que este analise e discuta as indicações para consagração de novos obreiros, aprovando-as ou não. Este dado confirma a questão apontada por Rolim (1985, p. 49), onde ele afirma que os diáconos e presbíteros são nomeados pela convenção. Durante a pesquisa, não encontrei registro ou informação de que em outras épocas fosse usado outro tipo de procedimento. 
O presbítero, cargo imediatamente superior ao do diácono, constitui-se o próximo nível, isso para aqueles que tiverem completado no mínimo 5 anos como membro da igreja (para algumas convenções), tendo a partir de sua ordenação as seguintes funções:

a) o ensino da palavra de Deus;

b) a administração de uma congregação ou centro evangelístico;

c) e a visitação aos enfermos.

Em relação a esta última tarefa, o que o difere do diácono é que quem alcança o presbitério recebe a autoridade eclesiástica de ungir os doentes. Este ato ritual consiste em colocar uma gota de azeite ou óleo perfumado sobre o dedo polegar da mão direita e em seguida tocar a testa do doente, repreendendo o mal "em nome de Jesus". Segundo a tradição assembleiana, este ritual pode produzir efeito curativo desde que o executante seja, ao menos, presbítero da igreja.

No caso de ser nomeado responsável por uma determinada comunidade de fiéis, lhe é outorgado o total comando administrativo sobre a mesma. Para assumir este cargo (e os próximos cargos na hierarquia da Assembleia de Deus), o fiel deve, de acordo com a tradição, ser casado com uma mulher assembleiana. Cabe salientar que nos casos em que o fiel, no pleno exercício de suas funções eclesiais se divorciar de sua esposa, há a possibilidade de que ele se mantenha no cargo, contudo, serão observados os pontos contidos na Resolução 001/2011 aprovada durante a Assembleia Geral Ordinária (AGO), organizada pela CGADB em 13 de abril de 2011, que aprovou as seguintes questões:

a) a CGADB só reconhece o divórcio no âmbito ministerial de seus membros, nos casos de infidelidade conjugal, previstos na Bíblia sagrada e expressos em Mt 5.31-32; 19.9, devidamente comprovados;

b) as convenções estaduais deverão esgotar todos os esforços possíveis no sentido de promover a reconciliação do ministro e sua esposa, antes de serem ajuizadas ações de divórcio;

c) esta CGADB não reconhece, no âmbito da vida ministerial de seus membros, a situação de união estável;

d) o ministro, membro desta CGADB, divorciado nos termos do disposto na ponto (a) desta resolução ou no caso, onde a iniciativa do divorcio partir de sua esposa (1Co 7.15), poderá permanecer ou não, na função ministerial, decisão essa, que ficará a 
cargo da convenção estadual da qual é filiado, facultando-lhe o direito de recurso para a mesa diretora e para o plenário desta convenção geral;

e) o ministro, vítima de infidelidade conjugal por parte de sua esposa, poderá contrair novas núpcias, respeitados os princípios bíblicos que norteiam a união conjugal, nos termos da permissibilidade permitida por Cristo, em Mt 5.31-32; 19.9, ficando cada caso a ser examinado e decidido pelas convenções estaduais;

f) e quando o ministro der causa ao divórcio, a sua permanência ou retorno ao ministério dependerá de exame e decisão da convenção estadual, facultando-lhe ampla defesa, sendo-lhe também assegurado o recurso para a mesa diretora e para o plenário da convenção geral.

A resolução vista acima, altera a antiga norma que proibia os ministros divorciados a manterem seus postos de liderança na Assembleia de Deus, contudo, é possível vislumbrar a cautela apresentada por esta alteração, deixando a cargo das convenções locais e primazia quanto à investigação dos fatos e a aplicação das devidas sanções.

Diante destas questões, cabe lembrar que a indicação do diácono ao presbitério é feita pelo pastor da congregação, que consulta o ministério local e a comunidade antes de indicar o obreiro para a convenção estadual. Se concordar com a indicação, o Conselho de Ética encaminha o processo à secretaria da igreja, ocorrendo praticamente o mesmo procedimento realizado com os diáconos: preenchimento e preparação da documentação, submissão à aprovação e, em caso de aprovação, cerimônia de consagração. A única diferença (em algumas convenções estaduais) é o acréscimo da assinatura de uma declaração-modelo, criada pela secretaria da igreja, na qual o obreiro assume que será o único responsável por qualquer falha que ocorrer no cumprimento do dever e que atenderá aos compromissos assumidos a partir da data da consagração, para com Deus, a família e a igreja, procurando viver dentro da ética cristã e concorda que, caso ausente-se das reuniões do ministério ou convocações do pastor presidente por três meses consecutivos, sem justa causa ou justificativa, estará sujeito à advertência e em persistindo a falta será suspenso do cargo.

O próximo nível e o de evangelista, que na maioria dos casos são prováveis indicados ao pastorado, e recebem a incumbência de gerirem uma congregação como auxiliar de um pastor ou como pastor. A indicação do evangelista deve ser efetuada pelo pastor presidente da convenção estadual em consentimento com o Conselho de Ética. O procedimento de aprovação e consagração é o mesmo do presbítero. 
Após cinco anos como evangelista (conforme alguns regimentos internos), o fiel pode ser indicado ao pastorado, indicação que também é feita pelo pastor presidente e deve passar pela aprovação da convenção estadual. Ao ser indicado, o futuro pastor necessita apresentar à convenção a seguinte documentação: Certidão negativa do sistema de proteção ao crédito (SPC-SERASA); Certidão negativa do tabelionato de protesto de títulos; Certidão negativa do cartório civil e criminal; em alguns casos, comprovante de pagamento do dízimo dos últimos doze meses; Certificado de conclusão do ensino médio e Certificado de conclusão do curso de Teologia ou curso equivalente devidamente reconhecido pela igreja. Sobre este ultimo requisito é necessário frisar que aí reside à mudança em relação aos primórdios da instituição. Existe agora a exigência do curso teológico, sendo esta exigência justificada pela forte institucionalização da Assembleia de Deus e a preocupação em compor um corpo de ministros qualificados para o exercício das atividades eclesiais. Mesmo assim, o curso teológico é encarado como ferramenta e não como elemento primordial ao exercício das funções.

Chegando ao pastorado o fiel alcança o topo na hierarquia eclesiástica assembleiana. Um pastor pode, por exemplo, receber este título e até o final de sua carreira trabalhar administrando igrejas, função esta que já efetuava na posição de evangelista. Pode também, com o passar do tempo, simplesmente ser destituído de suas funções caindo no ostracismo.

O final da carreira de um pastor, independentemente da sua importância na hierarquia da igreja é o jubilamento e a Assembleia de Deus se responsabiliza em ajudá-lo financeiramente. $\mathrm{O}$ pagamento de salário aos pastores inativos não chega a ser um peso para a igreja, pois geralmente eles deixam seus postos de trabalho já bem idosos, normalmente quando a doença ou a falta de lucidez os impede de prosseguir.

O tempo médio que se leva como obreiro na Assembleia de Deus entre a designação para auxiliar e o pastorado é de aproximadamente 12 anos.

\section{Conclusões}

Este trabalho analisou o conceito de trabalho e mercado religiosos e sua aplicação dentro do contexto pentecostal no Brasil, por meio da Assembleia de Deus em Palmeira dos Índios. O objetivo principal foi mostrar como a ideia de vocação incorpora uma série de fundamentos religiosos e morais capazes e dar fortalecimento aos chamados cargos ministeriais. Diante disso mostramos os principais requisitos para a obtenção dos cargos e 
suas ligações com questões como: vocação, autonomia administrativa, poder de consagração e manipulação simbólica.

Através das informações acima descritas foi possível observar que diferentemente de outras denominações, a Assembleia de Deus não prioriza de antemão a formação intelectual do candidato, mas sim os fundamentos morais de seu comportamento e junto a isso a situação espiritual que julga ser a ideal (domínio da glossolalia e o exercício dos carismas). O detalhe é que a observância do comportamento dentro da igreja é um dos parâmetros de escolha. Isso se evidencia no fato de que a vocação na verdade é observada conforme o individuo se aproxima ou não das funções próprias aos cargos que analisamos. Em outras palavras, se ele gosta dos serviços de assistência social e gerais da igreja, será então observado como um servidor, um diácono. Se este diácono se interessa pelo ensino da Bíblica e se compromete com a formação dos fiéis, poderá se tornar um presbítero. Se tem capacidade de arregimentar fiéis será um evangelista, bem como, se tem capacidade de organização e gestão, poderá vir a ser pastor. Desta forma o argumento não é o de nomeação de obreiros, mas o de reconhecimento de suas aptidões, que julgam não serem apenas relacionais mais principalmente espirituais.

Com isso podemos constatar a ideia de exercício ministerial como intimamente ligado à oferta de serviços eclesiais e a reprodução da lógica administrativa desta igreja, que presa pelo posicionamento sectário, manutenção de pontos doutrinários, centralidade administrativa, autocracia e uso de dons e carismas.

\section{Referências}

ALMEIDA, João Ferreira de. (Org.). Bíblia de Estudo Pentecostal. 24. ed. rev. e corr. Rio de Janeiro: CPAD, 1995.

ASSEMBLEIA DE DEUS EM ALAGOAS. Disponível em: 〈http://www.adalagoas.com.br〉. Acesso em: 26 abr. 2011.

AQUAVIVA, Sabino Samele. L`eclissi del sacro nella civita industriale. Milão: Comunitá, 1992.

BERGER, Peter L. O dossel sagrado: elementos para uma teoria sociológica da religião. São Paulo: Paulus, 1985.

BOURDIEU, Pierre. A economia das trocas simbólicas. São Paulo: Perspectiva, 2009. O poder Simbólico. São Paulo: Bertrand Brasil, 1989.

CONVENÇÃO GERAL DAS ASSEMBLEIA DE DEUS NO BRASIL. Disponível em: <http://www.cgadb.com.br>. Acesso em 30 mar. 2012.

DOBBELAERE, Karel. Secularization: a multi-dimensional concept. Nova York: Current Sociology, 1981. 
FRESTON, Paul. Protestantismo e Democracia no Brasil. Revista Lusotopie, 1999, pp. 329-340.

LAPLANTINE, François. Aprender Antropologia. São Paulo, SP, ed. Brasiliense, $21^{\text {a }}$ edição, 1988.

LUCKMANN, Thomas. La religione invisible: Bolonha: Il Munilo, 1969.

MARX, Karl. Manuscritos econômico-filosóficos. Tradução de Jesus Ranieri. São Paulo: Boitempo, 2004.

OLIVEIRA. Pedro A. Ribeiro de. A teoria do trabalho religioso em Pierre Bourdieu. In.

TEIXEIRA, Faustino (Org.). Sociologia da Religião. Petropólis: Vozes, 2007.

REGIMENTO INTERNO DA ASSEMBLEIA DE DEUS EM ALAGOAS. Maceió: Ingraf, 2005.

RESOLUÇÃO 001/2011: Convenção geral da Assembleia de Deus no Brasil. Cuiabá: 2011.

RESOLUÇÃO: Encontro de Líderes da Assembleia de Deus. Cuiabá: 2011.

ROLIM, Francisco Cartaxo. Pentecostais no Brasil: uma interpretação sócio-religiosa. Rio de Janeiro: Vozes, 1985.

SOUZA NETO, Arlindo de; AMARAL, Polyanny Lílian do. Os Imponderáveis da Etnografia Religiosa: Uma Análise Sobre o Trabalho Etnográfico no Campo da Religião. In: MNEME: Revista de Humanidades, 2011 - Janeiro-Julho. 